\title{
Cuentos de tradición oral recogidos en Pozuelo (Albacete)
}

\author{
M. ${ }^{a}$ Carmen Atiénzar García \\ Universidad Nacional de Educación a Distancia \\ carmenatienzar@yahoo.es
}

\begin{abstract}
RESUMEN
El objetivo principal de este artículo es dar a conocer algunos de los cuentos de tradición oral que perviven en la localidad de Pozuelo (Albacete). Se pretende, por un lado, ofrecer una visión general de las características que presentan estos cuentos $y$, por otro, mostrar algún ejemplo, analizado desde el punto de vista de su catalogación y difusión en el ámbito de la península ibérica. Dado que la pieza clave para la transmisión de los cuentos de tradición oral es el narrador, su estudio se abordará a través del análisis del repertorio y estilo de dos narradoras. Por otra parte, el estudio de los cuentos no se puede separar del contexto en el que surgieron; por eso se hará referencia a las ocasiones de encuentro que alentaron en el pasado la aparición de dichas narraciones, así como a las circunstancias en que se recuperaron las versiones que conforman el corpus objeto de análisis. El estudio de todos estos aspectos dará luz sobre el estado actual de pervivencia de la tradición en Pozuelo y sobre los elementos que acompañan la narración de un cuento y contribuyen a su transmisión y mantenimiento en cualquier zona geográfica.
\end{abstract}

PALABRAS CLAVE

cuento oral; trabajo de campo; ATU; narración oral; contexto

\begin{abstract}
The main aim of this paper is to bring to light some of the oral tales from the village of Pozuelo (Albacete). On the one hand, we provide a general view of the characteristics present in these tales and on the other hand we analyse some samples in terms of their cataloguing and their dissemination throughout the Iberian Peninsula. Given that the most important figure in the transmission of tales transmission is the narrator, the study of the tales will be based on a thorough analysis of the repertoire and style of two female narrators. Furthermore, the study of folktales cannot be separated from the context in which they were devised, thus there is a discussion of the social occasions in the past that helped foster the creation of these tales and of the circumstances in which the versions under analysis were recorded. The study of all these aspects sheds light on the current state of the oral tradition in Pozuelo and on the elements of storytelling that contribute to its transmission and continuity in any geographical area.
\end{abstract}

KEY WORDS

Oral tale; fieldwork; ATU; oral narration; context

REBUT: I4.09.2OI5 | ACCEPTAT: 06.IO.2OI5

Estudis de Literatura Oral Popular, núm. 4, 20I5, 33-48 | DOI: Io.I7345/elop20I533-48

ISSN: 2OI4-7996 | http://revistes.urv.cat/index.php/elop 


\section{Introducción}

Este artículo presenta el repertorio de cuentos de tradición oral contados por dos narradoras de una pequeña población de Albacete llamada Pozuelo. Estas dos mujeres narraron más del $50 \%$ del corpus que recopilé en esta localidad. Sin duda, el estudio de estas mujeres, sus relatos, su estilo narrativo y sus vivencias aportará algunos datos para el conocimiento de los cuentos de tradición oral en esta zona de Albacete y explicará las razones de su pervivencia.

Según Alan Dundes (I980: 22-24), toda investigación folclórica que se precie debe tener en cuenta tres aspectos: el texto, la textura y el contexto. Por consiguiente, se debe estudiar la performance (todo lo que acompaña la narración de cada versión), la lengua (aliteraciones, ritmo, tono, onomatopeyas, etc.), pero también el contexto social en el que se narraban. En este sentido, se tratará de analizar algunos de los textos de las narradoras (con toda la carga gestual que conllevan), su estilo y el contexto en que fueron grabadas, sin olvidar el contexto social en el que pervivieron durante muchos años.

La recopilación de cuentos en Pozuelo se llevó a cabo en dos fases: la primera, de octubre a diciembre de I998 (24 versiones); y la segunda, entre septiembre de 20I4 y enero de 2015 (8 versiones). El trabajo de campo más reciente se realizó para comprobar si seguían contándose los mismos cuentos. Se pretendía averiguar qué había cambiado y qué aspectos se mantenían dieciséis años después.

El método empleado fue la encuesta folclórica presencial y directa, pues aporta una serie de datos esenciales para la interpretación de los cuentos y favorece su posterior transcripción literal. En la encuesta se recogían tres puntos fundamentales: datos personales del narrador o narradora, transmisión del cuento (contexto) y narración en sí (si era el caso, se incluía título, ${ }^{\mathrm{I}}$ fórmulas iniciales y finales, ${ }^{2}$ etc.).

La zona de la encuesta comprendía únicamente Pozuelo, una localidad de la comarca de la sierra de Alcaraz, situada al suroeste de Albacete.

En I998, me facilitó la realización del trabajo de campo la utilización de «porteros», es decir, personas que me ayudaron a contactar con los informantes de esta localidad y a romper sus barreras psicológicas. La encargada de realizar esta labor fue Rosario Hernández. ${ }^{3}$ En un primer momento, las entrevistas se realizaron en su casa, donde convocaba a sus vecinas. En otras ocasiones, me acompañó a casa de otras narradoras, con las que había contactado previamente. A veces ella misma intervenía narrando otra versión del cuento que acababan de contar. Posteriormente, me ayudó Ascensión, ${ }^{4}$ quien con sus retahílas y cantares animaba a las vecinas a participar activamente en las reuniones.

En general, se procuraba siempre llevar a cabo las entrevistas en un clima de confianza, intentando que se convirtieran en una conversación distendida, recreando en la medida de lo posible las reuniones o las veladas en que surgían es-

\footnotetext{
I. Sobre los títulos en cuentos orales, $c f$. Lavinio (I990).

2. Sobre la dificultad de establecer las fronteras de una narración oral, $c f$. Lavinio (I997: 25) y Sanfilippo (2007b: I4I).

3. 68 años, sin estudios, ama de casa. Además, trabajaba con su marido en el campo.

4. Desconozco sus apellidos. No sabía cuentos, pero buscó incansablemente entre sus vecinas hasta localizar algunas narradoras. Ella tenía un amplio repertorio de cantares y romances.
} 
pontáneamente los cuentos y otras manifestaciones de la cultura tradicional. Así pues, para fomentar la naturalidad de la entrevista, se intentaba recoger los datos sobre las narradoras al hilo de la conversación, tratando de no invadir en exceso su intimidad, lo que explica que en algunos casos no se pudieran obtener todos los datos buscados.

Cuando regresé a Pozuelo en 20I4, la situación había cambiado. Rosario Hernández ya no residía allí y otros colaboradores, desgraciadamente, habían fallecido. Sin embargo, no me resultó difícil entablar conversación con nuevas narradoras y volver a recuperar las reuniones de años anteriores.

\section{El contexto}

Según las personas entrevistadas, los momentos más propicios para la narración de cuentos eran la monda de la rosa del azafrán, la matanza del cerdo o las reuniones familiares o de vecinos que tenían lugar cuando terminaban las faenas agrícolas al atardecer; también contaban historias las mujeres en el lavadero del pueblo, mientras lavaban la ropa. Sin embargo, la monda de la rosa, una labor colectiva realizada tradicionalmente por mujeres, niños y ancianos, era el contexto más idóneo para la narración de cuentos populares, con los que se distraía a los niños y se acompasaba la monotonía del trabajo. A propósito de esta tarea, se pueden hacer reflexiones similares a las realizadas por Carlos González:

El cuento exige el contacto directo entre su narrador y su auditorio, que no son precisamente entes abstractos, sino personas de carne y hueso que dialogan o conversan o, si se prefiere, colaboran acompasando su ritmo con el ritmo de sus palabras, es decir, convirtiéndose en verdadera comunidad (González 2006: 209).

En este sentido, la tarea de la monda de la rosa del azafrán constituiría una metáfora que nos ayudaría a entender la verdadera dimensión de una narración popular, tanto por el tiempo y espacio en que se realizaba como por su proceso de limpieza, de separación, con las propias manos, de los tres estigmas de la rosa, en busca del preciado azafrán. A esto se debería añadir su carácter comunitario y conversacional. Con todo, la narración se asemeja especialmente a dicha tarea por ser

un proceso, algo que se está haciendo, que se está desenvolviendo rítmicamente. En efecto, por narración popular no podemos entender solo cada momento en que esta es contada, sino la larga historia de narraciones y audiciones en que el relato ha ido construyéndose como un producto de la memoria y, por tanto, de los deseos y la mentalidad de los hombres en el seno de la cultura tradicional (González I996b: I5-I6).

Actualmente, esta importante ocasión de encuentro ha desaparecido en Pozuelo. Sin embargo, todas las tardes las vecinas se siguen reuniendo en los patios, en la puerta de las casas o a la sombra del árbol situado al pasar la plaza. Por eso, no resulta difícil encontrarlas y hablar con ellas. No hay que insistir mucho para que se lancen a cantar coplas o romances, o para que te obsequien con algún cuento, porque afortunadamente estas muestras de la tradición oral siguen formando parte de la vida cotidiana de esta localidad. 


\section{Las narradoras}

En Pozuelo conseguí recopilar cuentos de cinco narradoras. ${ }^{5}$ Los hombres estuvieron presentes en casi todas las reuniones, animándolas con algún comentario gracioso, pero se mantuvieron al margen. Quizás los intimidaba la grabadora aunque, según ellos, el problema era que no sabían contarlos bien. Posiblemente el contexto no era el adecuado para que se decidieran a tomar la palabra, cuando la persona que recopilaba era una mujer. Tal vez les daba vergüenza contar algún cuento «colorao», que no me pareciera apropiado. $\mathrm{O}$, simplemente, no se daba una condición indispensable que apostilló uno de ellos: «El cuento tiene que venir a cuento».

Existe siempre una diferencia entre los narradores reconocidos y las personas que simplemente conocen y pueden contar un cuento. ${ }^{6}$ En este sentido me parece oportuno presentar a las dos auténticas narradoras de Pozuelo.

\subsection{Paula Riscos Córcoles: la pasión por los cuentos}

Más del 40 \% de los cuentos recopilados en Pozuelo fueron narrados por Paula Riscos Córcoles, una mujer que siente una verdadera pasión por ellos.

Nacida y criada en esta localidad, aprendió sus relatos durante las faenas agrícolas o en la monda de la rosa del azafrán. Su madre también solía contarle cuentos (sobre todo de animales). ${ }^{7}$ Reconoce tener muy buena memoria y, por eso, todo lo que escuchaba lo retenía. No sabe leer ni escribir. Aun así, no se explica cómo, es «capaz de encontrar una poesía, un chiste o un cuento apropiado para cada situación de su vida». Tal vez la explicación que ella no encuentra es que ha logrado hacer que todo ese material tradicional siga teniendo una razón de ser en su vida. Los cuentos le siguen siendo útiles, le siguen diciendo algo sobre sus experiencias cotidianas. En su caso, los cuentos no han perdido su funcionalidad y sigue existiendo un vínculo entre ellos y sus vivencias.

En el pueblo tiene fama de saber muchos cantares e historias de antes. Incluso algunas vecinas reconocen que los cuentos que saben los aprendieron de ella. Por tanto, Paula fue oyente de lo que narra y, habiendo asumido la responsabilidad de aprenderlo y volverlo a contar, exige a sus oyentes que asuman la responsabilidad de convertirse en futuros narradores.

El legado de tradición oral que atesora lo conserva y lo transmite como un bien preciado, que generosamente regala, orgullosa de compartirlo, a todo aquel que quiera disfrutar de su compañía.

5. Paula Riscos Córcoles, 68 años, sin estudios, ama de casa; Avelina, unos 80 años, sin estudios, ama de casa; Rosario Hernández, 68 años, sin estudios, ama de casa; María, 64 años, estudios primarios, ama de casa; María Peña Martínez, 8I años, sin estudios, ama de casa. Todas ellas trabajaron en faenas agrícolas, especialmente en la monda de la rosa del azafrán.

6. Cf. Mugnaini (2004) y Sanfilippo (2014: I72).

7. Sobre la transmisión de cuentos y repertorios dentro de una familia, $c f$. Venturelli (I987) y Sanfilippo (2007a). 


\subsubsection{Su repertorio}

Su repertorio es amplio y variado: cuentos de animales, de magia, chanzas y anécdotas (cuentos de tontos y de curas) se entremezclan en su memoria y salen por su boca para deleite del auditorio. Sus narraciones se van alternando con cantares, adivinanzas, romances, poesías... En general, los personajes de sus cuentos se caracterizan por la maldad o por su ignorancia.

El repertorio de Paula incluye 3 cuentos de animales, 4 cuentos folclóricos ordinarios (cuentos de magia) y 6 chanzas y anécdotas. Veamos el resumen de cada versión con la indicación de tipos y motivos según el catálogo ATU.

La zorra y el lobo (ATU $3+4+30$ ). Los dos animales van de caza y encuentran unos pastores. La zorra, no temiendo el fuego, entra en el corral de ganado y se harta de gazpachos. Se echa en la cabeza los que le quedaron y hace creer al lobo que le han dado una paliza y le han echado los sesos de fuera [K473]. De esta manera lo convence para que la lleve a cuestas [KI24I] con el pretexto de que está malherida [KI8I8]. Mientras cabalga sobre su ingenuo compañero canta una canción burlona alusiva a la cómica situación. Por último, llegan junto a un pozo y la zorra le pide ayuda al lobo para bajar a beber. Así lo hace, pero, cuando baja el lobo, la zorra no le da la ayuda prometida y este se queda en el fondo.

El burro y el lobo (ATU 47B). Un burro viejo, herido porque lleva un clavo en la pata, se encuentra con un lobo que intenta devorarlo. El burro le pide que antes de morir le arranque el clavo que tiene clavado en la pata [K566]. Entonces cocea al lobo [KII2I] y lo mata.

La cabra y los siete cabriticos (ATU I23). La cabra sale a buscar comida y deja a sus siete hijos solos en casa con la advertencia de no abrir la puerta al lobo. El depredador intenta engañar a los cabritillos diciéndoles que es su madre, pero lo reconocen por la voz y por las patas negras, y no lo dejan entrar [Ji44]. Entonces el lobo come muchos huevos para cambiar la voz [KI832] y se echa harina en las patas [KI839.I] para lograr acceder a la casa. Lo consigue [K3II.3] y se come a todos los cabritillos [F9II.3], menos a uno, que se esconde en la caja del reloj. Cuando regresa la madre y se entera de lo sucedido, corre a buscar al lobo, que está durmiendo, le raja la barriga [Q426], saca a sus hijos vivos [F9I3] y pone piedras en su lugar [Q426]. Cuando se despierta el lobo, acuciado por la sed, va a beber agua a un pozo, cae por el peso de las piedras y se ahoga.

Barbazul (ATU 3II + 3I2). Una mujer entrega a su hija como criada a un hombre malvado, quien le prohibirá entrar a una de las habitaciones de la casa [C6II] y le pedirá que haga puntilla durante su ausencia. La joven, que no puede controlar su curiosidad, entra en la habitación y descubre muchos cadáveres de niños. Barbazul descubre que la chica ha transgredido la prohibición cuando ve la puntilla manchada de sangre [C9I3]. La mata inmediatamente [C920]. Después entra a servir en casa del asesino una hermana de la joven, y sucede lo mismo. Por fin, la tercera hermana, que es la menor, se introduce en la habitación, ve a sus hermanas muertas, sube a la parte alta de la casa y empieza a pedir auxilio. De esta manera, consigue salvarse [G550].

Los tres osetes (sin catalogar). Una niña se introduce en la casa de una familia de osos [B20o] durante su ausencia. Cuando regresan, encuentran a la niña acostada en la cama del osito. La niña se asusta y les pide que no la maten. Deciden no 
hacerle daño, a condición de que todos los días juegue con su pequeño [B2II.2.3, B538].

Caperucita (ATU 333). La madre de Caperucita envía a esta última a casa de su abuela a llevarle el desayuno y le indica qué camino debe seguir [J2I.5]. En una encrucijada se encuentra con el lobo, que la engaña indicándole la ruta más larga. El lobo se adelanta a casa de la abuela, la devora, se pone su ropa y se mete en su cama. Cuando llega la niña se extraña del aspecto de su abuela [ZI8.I] y le va preguntando, mediante un diálogo formular, por las exageradas dimensiones de sus ojos, de sus manos... Cuando menciona la boca, el lobo se la come [K2O22]. Un cazador que pasa por allí oye los ronquidos del animal, lo mata y saca vivas de su barriga a Caperucita y a su abuela [F9I3].

El demonio (cf. ATU 706). Un padre tiene tres hijas, pero no tiene para darles de comer. Mientras recoge leña, se le aparece el diablo [G303.3.I] montado en un caballo blanco [G303.7.I] y le pide que al día siguiente le traiga la mano de su hija mayor [SI6I]. El padre le corta la mano a su hija [SII.I] y le entrega al diablo la joven a cambio de una bolsa de oro [S2II, S22I]. Al día siguiente hace lo mismo con su segunda hija. Por último, el diablo le pide a su tercera hija, pero sin mutilar. El padre se la entrega. El diablo se la lleva montada en su caballo pero, cuando esta empieza a invocar a Dios, la Virgen y los santos, el diablo desaparece [G303.I6.8], ella cae del caballo en una cueva donde había muchos animales y se salva [G303.I6.2.2].

El padre de la estatua (ATU I347*). Un gitano pide a un santo que le dé el dinero del cepillo. Como no le da nada, lo amenaza con darle dos palos. Va corriendo a su casa a por la garrota para romper la imagen [VI2O], momento que aprovecha el cura (que ha contemplado la escena) para llevarse la estatua y colocar una más pequeña en su lugar [KI840]. Cuando regresa el gitano, pregunta al nuevo santo por su padre [JI794].

Las tres tontas (ATU I457). La madre advierte a sus tres hijas [P252.2] que no digan nada cuando sus pretendientes entren en casa [KI984]. Sin embargo, un suceso fortuito hace que las jóvenes hablen [JIO82] y se revele su deficiente pronunciación [KI984.I].

La visita del amigo (variante de ATU I699). Un hombre recibe en su casa a un amigo. Lo invita a comer y se queda a dormir porque se desata una fuerte tormenta. Se acuesta en la cama, entre su amigo y su mujer [T28I]. En mitad de la noche, llaman a la puerta. El marido se levanta a abrir y la mujer le pide al amigo que aproveche la ocasión [T230]. El amigo corre a comerse la tortilla que había quedado de la cena [Xiıi.7].

La tonta que se iba a casar (sin catalogar). Una pareja de tontos [Ji7oo] decide casarse. La novia [J2463] se lo comunica a su madre la víspera y se disponen a preparar todo lo necesario para la boda [T132]. Mientras maja unos dientes de ajo, entona una cancioncilla alusiva al acto sexual [Ti6o].

El parto del cura (ATU I739). A un cura le diagnostican un embarazo [T578] porque sustituyen su orina por la de una mujer que estaba embarazada. El cura quiere abortar y le pide al sacristán que le dé una paliza muy grande. Cuando está medio muerto por el palizón, ve una cucaracha y cree que ha parido al ver que el insecto lleva «sotanas» como su padre [J232I.I]. 
Quien te conoció ciruelo $^{8}$ (González I824A; Robe I829*D). Un hombre tenía un ciruelo que no daba fruto. Por eso, decide arrancarlo y hacer un santo con el tronco [VI27]. Cuando ve al santo en el altar, desconfía de los milagros que este pueda hacer [Ji880] porque conoce bien su origen.

Con el paso de los años, Paula sigue contando los mismos cuentos de animales y chanzas y anécdotas casi con las mismas palabras. Sin embargo, no recuerda los cuentos de magia, es decir, justo los cuentos más difíciles de contar. No ha sido capaz de repetir ninguno de los que me contó en i998. Recuerda los personajes y algún motivo, pero es incapaz de recordar la trama. Esto demuestra la desaparición de este tipo de cuentos en los contextos actuales.

\subsubsection{Su estilo narrativo}

El estilo de Paula Riscos Córcoles se caracteriza por una expresión sencilla, escueta y llena de repeticiones. Se suele acompañar con gestos y movimientos de los ojos y de los brazos, que añaden un toque de picardía y de gracia difíciles de describir.

Desde el punto de vista sintáctico, utiliza varias estrategias para hacer avanzar la narración. Unas veces retoma la frase final del estilo directo cuando comienza a narrar nuevos hechos: «-Llévame en cuestas» / «Y la echa en cuestas» (La zorra y el $l o b o$ ). Otras veces se vale de preguntas retóricas a las que responde inmediatamente: «Y ¿qué hizo? Hincarle un clavo y lo dejó cojico» (El burro y el lobo). Por otra parte, usa con frecuencia el estilo directo, cambiando la voz según las características de cada personaje (recrea la voz de la zorra que finge estar enferma, del lobo, de los cabritillos, de personas tontas... Incluso imita el acento de los gitanos en El padre de la estatua). Su discurso directo se interrumpe constantemente con el verbo dice, automatizado y desemantizado, que le sirve para resaltar la entonación de las frases sobre las que quiere llamar la atención. Además, repite con frecuencia la conjunción y; utiliza interjecciones («iAy!, ¡Hala!»), exclamaciones («iToma!») y diminutivos, lo que aumenta la expresividad y la tensión emotiva del cuento.

Otro rasgo que caracteriza el estilo de Paula es la presencia de cancioncillas en los cuentos de su repertorio: "Zorra grillera, harta de gazpachos / y bien caballera». Sin embargo, no utiliza fórmulas de cierre. Suele comenzar con «Era» / «Esto era», para terminar diciendo «Yya», a lo que alguno de los presentes a veces respondía: «Y cuentecico colorao, por la boca tuya se ha colao». Esto se podría interpretar como una necesidad de que la conclusión la dé el auditorio, bien mediante una fórmula de cierre o bien con la risa, como respuesta al cuento narrado. Otras veces termina explicando lo que pasó, adoptando un punto de vista realista: «Y ya vinieron la pulicía y se la llevaron y esa se salvó, pero las otras no» (Barbazul).

Reproduzco a continuación uno de sus cuentos:

8. En este cuento se observa un ejemplo de apropiación, ya que todas las versiones recogidas en la provincia de Albacete, incluida la de Paula, sitúan la anécdota en Pozuelo. La desconfianza del hombre se expresa con estas palabras: «Quien te conoció ciruelo en el huerto de mi abuelo, y hoy te veo de Santocristo en El Pozuelo». La frase se usa para censurar a quien ocupa un puesto importante sin ningún mérito (cf. Rodríguez 2000: 276-280). 


\section{[Las tres tontas] $]^{9}$}

Esto era una madre que tenía tres tontas, tontas perdías. Y dice la madre:

— ¿Pos qué voy a hacer yo con los tontuzos estos? Yo le voy a buscar unos novios.

Y va la madre y busca uno... Les busca unos novios. Y dice, dice la madre:

-Mirar, vusotros no tengáis que hablar, na más que echarle lumbre a la olla - que puso una olla pa darles de comer a los novios-, que van a venir vuestros novios, que los he buscao unos novios.

Y se va la madre a por cosas para darles a los novios. Y ya... estaban así toas [la narradora adopta una posición erguida, con las manos extendidas apuntando hacia abajo, mientras mueve los ojos hacia derecha e izquierda con picardía]. Vienen los novios y no viste qué corte le hacía su novio. Ellas no querían hablar, ¡ummmm! [aprieta con fuerza los labios emitiendo un sonido parecido al de un moscardón]. Y ya dice:

- ¿Qué...?

La otra decía:

—No ha... no hables, que la mama nos pega.

Ice:

-Tú, callaté.

Y la... y la más grande, la mayor, ya se..., enga a meterle a la olla... a la olla leña. (Luego un cabrerío tenían, se quemaban...). Y los novios allí. Pero ya, ¿por qué no?, se sale la olla, y dice la grande:

—iQue se sale la yolla!

Dice la otra:

- ¡Quítale la torretera!

Dice:

- ¡No meterle la cucharra!

(Dice que no metiera la cuchara y que le quitara la cobertera a la olla). Y dice... Y ya viene la madre y dice:

-Pero bueno, ¿ánde están los novios?

Y dice:

- ¡Se han ido a los cuatro pies!

- ¿No los he dicho que no hablarais?

Dice:

-Mama, se saliba la yolla.

-Y yo le he dicho que le quitara la torretera.

-Y yo que le metiera la chucharra [imitando la voz de un niño pequeño].

¡Hala! Pos ya.

\footnotetext{
9. Se conocen numerosas versiones del tipo I457 en los siguientes catálogos tipológicos: Cardigos (2006: 305-306): I2 versiones; Oriol-Pujol (2008: 245-246): I versión de Cataluña, 2 de Mallorca y 2 de Valencia; Noia (2010: 658-66o): 9 versiones orales y 5 literarias; Hernández (20I3: 220): I3 versiones orales recogidas en Jumilla, Caprés, Torre Pacheco, Mula y Cartagena. Otras versiones no incluidas en los catálogos citados: Agúndez (I999): II, núm. I92; Asiáin (2006): núms. 89-90; González (20I0): II, p. I38-I39; Hernández (200I): núm. I5I; Pérez-Martínez (2006): núm. 55; Rodríguez (2002): núms. I8-I9.
} 


\subsection{Avelina o el «resurgir» en la narración}

Tras la primera entrevista con Paula, Rosario Hernández me acompañó a casa de Avelina, una mujer de unos 80 años que desde hacía ya varios se encontraba encamada, sin apenas movilidad, tras haber perdido la vista. Su hija, amablemente, nos condujo a su habitación, advirtiéndonos de que no sabía cómo reaccionaría. Tenía un carácter muy fuerte y muchas veces, a causa de la enfermedad, se negaba a recibir visitas; y si hablaba con algún vecino lo hacía por poco tiempo. Todavía hoy su hija se maravilla ante la reacción de su madre y no entiende cómo accedió a hablar conmigo. Sin embargo, desde que me acerqué a ella para explicarle el objeto de mi investigación, se estableció una especie de hilo invisible que nos unía: en un extremo ella, que apretaba con fuerza mi mano para asegurarse de mi presencia; en el otro extremo yo, emocionada al sentir la transformación que se estaba produciendo en ella, y entre las dos, un hilo mágico e invisible repleto de romances, coplas y narraciones de tradición oral. Es todo lo que se necesita: un buen narrador, un receptor entregado y una historia que contar. Quizás es necesario también el contacto físico, porque no soltó mi mano ni un momento. De este modo, no solo sentía la presencia de un auditorio, sino que también marcaba un ritmo en la narración, pues yo notaba cómo apretaba mi mano con más fuerza en el clímax de cada cuento.

Sin duda, ella ha sido la narradora que más me ha conmovido durante mi trabajo de campo. La experiencia me hizo creer en el poder terapéutico de los cuentos, no solo para quien los escucha sino, sobre todo, para quien los narra. Cuando entré en la habitación, encontré a una persona enferma, desvalida, sin fuerzas para nada. Sin embargo, a medida que iba desgranando sus cuentos, se transformaba. Asistí a un resurgir inexplicable. Tal vez la clave reside en que recordar significa «volver a pasar por el corazón». ${ }^{\text {Io }}$ Ciertamente, a través de la memoria de los cuentos, Avelina estaba pasando por su corazón el encanto de aquellas veladas de antaño, en las que ella era el centro de la reunión y deleitaba con sus narraciones. Todo había cambiado, pero, gracias a los cuentos, se volvía a poner en medio de la vida y recuperaba un rol que siempre había tenido en su entorno más cercano.

\subsubsection{Su repertorio}

El repertorio de Avelina se compone de 3 cuentos de magia, I chiste sobre curas y 2 cuentos acumulativos. Veamos el resumen de cada versión.

La cueva de los gatos (variante de ATU 480). Un zapatero pobre se asoma a un pozo y se le cae en él un ovillo que llevaba para coser los zapatos [N777.3]. Entra en el pozo y accede a una cueva donde viven unos gatos, criados de unos reyes [B574]. El protagonista alaba la belleza de los gatos y recibe un burro cargado de monedas de oro [Q4I, B35O]. Cuando regresa a casa, le cuenta lo sucedido a su mujer y después a su hermano, que era muy rico y envidioso. Este va a buscar a los gatos, pero les dice cosas desagradables y es castigado [Q280].

Estrellita de Oro (ATU 480 + 5IOA). Animado por su hija, un hombre viudo se casa en segundas nupcias con la vecina, que también tiene una hija. La madrastra [S3I, H934.3] envía a la hijastra a lavar tripas en el río. Se le escapa una tripa [N79I]

Io. $C f$. lo que afirma una narradora no tradicional como Virginia Imaz a este propósito (2005: 4I). 
y se le presenta la Virgen [N8I7], que, por su bondad, le coloca una estrella en la frente [Di86o]. La envidiosa hermanastra quiere imitarla pero, por su descortesía, recibe como castigo un rabo de burro en la frente [Q56I.8]. Un día el príncipe las invita a un baile, pero a Estrellita de Oro no le dejan ir. La protagonista, gracias a la varita de virtud, consigue una indumentaria adecuada para ir al baile [Dio50.I]. El príncipe se enamora de ella [N7II.6], pero tiene que marcharse temprano [C76I.3] y, en su huida, pierde un zapato. La escena se repite tres veces [R22I]. El príncipe recorre todos los hogares para probarle el zapato a todas las jóvenes [H36.I]. Cuando llega a la casa de la joven, la madrastra y la hermanastra no le dejan verla. El zapato le entra a la hermanastra, pero una perra revela con voz humana dónde está Estrellita de Oro. Se prueba el zapato y se casa con el príncipe.

El Medio Pollico (ATU 7I5). El Medio Pollico [BI7I.I] se encuentra un medio bolsillico mientras barre en su basurero. En ese momento pasa el hijo del rey y se lo quita. El Medio Pollico emprende viaje a palacio para reclamar lo suyo. Por el camino se encuentra con un lobo [B435.3], una zorra [B435.I], un gato [B422] y con diversos objetos [D9I5.2] que se mete en su medio culico [F9Io] y que, una vez en palacio, lo salvarán de la muerte ordenada allí (el lobo devorará las mulas que iban a pisotearlo, el río apagará el horno donde pretenden asarlo [Di382.8], etc.). Al final el príncipe se ve obligado a devolverle su medio bolsillico [K48I].

¡Ay, Mariquita mía! (variante de ATU I730 + I440). El cura molesta a una joven con insinuaciones. Esta se lo cuenta a su padre y ambos acuerdan que finja que accede a las intenciones del clérigo. Este va a casa de la muchacha y le promete al padre dinero para comprar una casa a cambio de lo que tenga en más estima. El padre acepta y al día siguiente le manda con los criados una burra en vez de mandarle a su hija, como se esperaba el cura.

El Garrampón (ATU 2O28). Un animal devora [Z33.4] sucesivamente [Z2O] a las tres hijas [P252.2] y a la madre de una familia. Al final es una humilde hormiga la que ahuyenta a picotazos al intruso.

\subsubsection{Su estilo narrativo}

Avelina narra con rapidez, transportada por la memoria. Los textos son bastante largos y los cuenta con seguridad y aplomo. La trama se presenta de forma lineal. Su estilo se caracteriza por el uso de fórmulas, reduplicaciones y, sobre todo, triplicaciones. Las repeticiones le sirven para amplificar la dimensión del espacio y del tiempo: «Y ella venga to los días dale, dale, dale» (Estrellita de Oro); para subrayar la relevancia semántica de los términos duplicados: «uno era mu pobrecico, mu pobrecico, y el otro mu rico, mu rico» (La cueva de los gatos); o para aumentar la espera y la tensión del auditorio ante el desarrollo de nuevos hechos: «-iAy, socorro! jSocorro! ¡Socorro!» (¡Ay, Mariquita mía!). La repetición también es esencial en la estructura de los dos cuentos acumulativos que me contó. También aparecen rimas internas («一;Gua, gua, gua! / La Estrellica de Oro / debajo l'artesa está / y el Rabo de Burro / en el coche va») y, sobre todo, predomina el estilo directo, sin ningún verbo que le dé paso. La transición del estilo directo a la diégesis se marca con «Bueno» o, menos frecuentemente, con «Conque». Utiliza interjecciones («jAy!, ¡Uh!»), exclamaciones («iUuuuuh, qué gato más hermoso!»), onomatopeyas («iTras, tras!», «iGua, gua, gua!»). 
A pesar de haber perdido la vista, describe la apariencia exterior de sus personajes con detalle. Ella, que no podía ver, hablaba al sentido de la vista. Sus cuentos distinguen el bien del mal y presentan características visuales: una estrella de oro en la frente, un rabo de burro, unos gatos muy guapos...

Sus cuentos suelen comenzar con: «Esto era». No utiliza fórmulas de cierre, ni introduce estrofas cantadas. Sin embargo, su repertorio está repleto de fórmulas, rimas y sonoridad.

\section{[Estrellita de Oro] ${ }^{11}$}

Esto era una vecina y un vecino. Y la vecina estaba viuda y el vecino tamién y cada uno tenía una hija, el vecino una hija y la vecina otra. Bueno, pues ya va la hija y le dice al padre:

-Padre, case usté con la vecindica que me da cucharicas de miel.

II. Julio Camarena y Maxime Chevalier (I995: 36I-362) señalan una amplia relación de versiones orales del tipo [480A] «Las dos hermanastras» de las áreas lingüísticas del castellano (26 versiones), del catalán (II vv.), del gallego ( 2 vv.) y del vascuence (2 vv.). Además, incluyen I4 versiones sefardíes, 39 hispanoamericanas y i3 portuguesas. Por otra parte, existen referencias del tipo ATU 480 en los siguientes catálogos tipológicos: Cardigos (2006: II3II5): Io versiones; Beltrán (2007: 603-604), núm. 63: 5 versiones valencianas y 23 del área lingüística catalana, para cuyo estudio remite a Oriol-Pujol (2003), 480, y I versión sevillana; Oriol - Pujol (2008: IO4-IO5): I7 versiones orales de Cataluña, 4 de la Franja de Aragón, 6 de Mallorca, I de Menorca, 2 de Ibiza, 5 de Valencia, I del Carche, I de Alguer y 3 versiones cuya procedencia no se especifica; Noia (20IO: 2I7-220): 2 versiones orales y 5 referencias de versiones literarias; Hernández (2013: IO5-IO6): I6 versiones orales, 2 de las cuales catalogadas por Camarena-Chevalier y i versión en valenciano, del Carche, ya citada.

En cuanto al tipo ATU 5IOA, Julio Camarena y Maxime Chevalier (I995: 4I2-4I3) ofrecen una relación de las versiones orales de las áreas lingüísticas del castellano (23 vv.), del catalán (II vv.) y del vascuence ( 3 vv.); 7 versiones sefardíes, 44 hispanoamericanas y 7 portuguesas. Además, figuran referencias en los siguientes catálogos tipológicos: González (I996a: 86), tipo 5II «Estrellita de Oro»: I referencia en nota a un cuento, I versión oral y 2 citadas; González (I998: 24), tipo 5IOA «Cenicienta»: 7 versiones en catalán (señala que todas las versiones que catalogaban como AT $5 \mathrm{II}$ pasan a ser catalogadas como CamarenaChevalier [480A] + AT 5IOA); Cardigos (2006: I2I-I23), tipo 5IOA: 26 versiones orales y I variante literaria; Beltrán (2007: 607-608), núm. 67, tipo 5IOA: 4 versiones valencianas (en el área lingüística del catalán, cita 7 versiones de Cataluña, 4 de la Franja de Aragón y 2 de Mallorca, remitiendo a Oriol-Pujol (2003), 5IOA) y 5 versiones de otras áreas lingüísticas peninsulares (no catalogadas por Camarena-Chevalier), recogidas en Sevilla (2 vv.), Valladolid, La Rioja y Aragón; Oriol-Pujol (2008: IIO-III): I8 versiones de Cataluña, 5 de la Franja de Aragón, 5 mallorquinas y 4 versiones cuyo origen no se especifica. Añaden una versión de Vinalopó Mitjà a las que señalaba Beltrán (2007) en el área geográfica valenciana; Noia (2OIO: 23I-234): 2 versiones orales y 6 literarias; Hernández (2OI3: IIO): 9 versiones orales en castellano y i en valenciano.

Sin embargo, de todas las versiones señaladas, en el Catálogo de Camarena-Chevalier (I995) solo presentan la misma estructura de la versión de Pozuelo [ATU 480 + 5IOA] las siguientes: en el área lingüística del castellano, 6 versiones recogidas en Granada, Cuenca, Asturias, Ciudad Real, Jaén y Córdoba; en el área del catalán, 3 versiones de Lérida e Ibiza; y I versión del área del vascuence. Además, 2 versiones de Marruecos y, en el ámbito hispanoamericano, 3 versiones de Puerto Rico, I de Chile y 3 de Argentina. Por último, aparecen 3 versiones portuguesas. En cuanto al área del catalán, encontramos 2 versiones de Cataluña, 2 de Ibiza, I valenciana y 3 versiones de procedencia sin especificar. De las versiones murcianas citadas por Hernández (20I3), solo 2 presentan la misma estructura de nuestra versión. Otras versiones semejantes a la de Pozuelo son: Asiáin (2006): núm. 29; Carrillo (2004: 5368); Pérez- Martínez, (2009): núm. 2I. 
- Hija mía, alguna vez te la dará de hiel.

-Padre, case usté con la vecindica que me da cucharicas de miel.

- Hija mía, alguna vez te la dará de hiel.

Bueno, ya va y dice:

-Bueno, sí. Te voy a hacer unos zapatos de hierro y, así que los rompas, me caso con ella.

Pos le hace unos zapatos de hierro su padre. Y ella venga to los días dale, dale, dale, con un guijarro y to para romperlos. Bueno, pos ya llega que los rompe y se casa el padre con la... con la vecindica, con la vecina.

Y compra la vecina, su madrastra, compra un menudo y le dice:

- Ves, ves y lávalo al río. Y como te se caiga una miaja tripa ¡te mato!

Bueno, ya se va, se arrodilla a lavarlo y se le escapa una miaja tripa. Y venga a llorar, y venga a llorar. Y... y se le presenta la Virgen:

- ¿Por qué llora usté?

- Mire usté, porque tengo mi madre señora y me ha mandao a lavar este menudo y, si me se cae una miaja tripa, me mata.

- Varica la virtú, con la gracia que tú tienes y la que Dios te va a dar, que te salga la tripa.

Y le salió la tripa. Y le dice:

-Cuando rebuzne el burro, metes la cabeza y cuando cante el gallo la sacas.

¡Y sacó una estrella de oro en toa la frente ella! Pues ya se va allí y la otra, la..., la hija —esa era la hija del vecino- y la hija suya verdá:

— ¡Ay, madre, qué estrellica de oro! ¡Ay, madre! — dice-, cómpreme usté tamién otro menudo a mí, que vaya yo tamién. ¡Oh, qué estrellica de oro! ¡Ay!

Bueno, pos ya le compró la madre otro menudo a ella y va:

-Tú, ves al río, como te se caiga una miajica tripa, ¡te mato!

Bueno, pues ya se va. - En ver de... era lo que le decía la madre-. ¡Ay!, venga a llorar, venga a llorar. Se presenta otra vez... Se presenta otra vez la Virgen:

— ¿Qué te pasa?

- Mire usté, que me ha mandao mi madre a que lave este menudo y, si me se cae una miaja tripa, ¡me mata!

- Varica la virtud, con la gracia que tú tienes y con la que Dios te va a dar, que te salga la tripa.

Bueno, pues le sale la tripa. Y dice:

-Cuando cante el gallo, metes la cabeza y, cuando rebuzne el burro, la sacas.

¡Y sacó un rabo e burro en to la frente, grandismo!

Pos ya, la pobrecica, no le querían dar de comer ni na, siempre la tenían debajo la artesa, allí. Y ellas... Oye... Y decía la hija: baile.

— ¡Ay, Estrellita de Oro! Mira, ha venido el hijo del príncipe a invitarnos a un

- ¡Ay, madre mía!

— ¡Tú! ¿Ande vas a ir tú? ¡Debajo la artesa! ¡Ay! ¿Ande vas a ir tú, gorrinón, que no tienes na que ponerte ni na?

Bueno, pues ya se van la madre y la hija al baile. Y ya... sale la Estrellica de Oro:

- Varica la virtú, con la gracia que yo tengo y con la que Dios me va a dar, que me ponga la Virgen la más guapa que haya en el baile.

Bueno, pues ya baja la Virgen. Le pone pulseras, collares, vestidos, zapatos, bueno, de to. Bueno, pues ya va, se va al baile. Y le dijo la Virgen: 
-A tal hora, ven.

Ya se va. Pos, ¡madre mía!, el hijo del rey en cuanto la vio. Pos, venga, venga, venga a bailar, venga a bailar. Pos ya dice:

-Pues esta noche no me se va a escapar.

Y puso pez y se le pegó el zapato, pero ella se fue a aquella hora.

Bueno, pues ya llegan que se van. Y después llegan la madre y la hija:

— ¡Ay, Estrellica de Oro, si hubieras visto! ¡Madre mía y qué muchacha más guapa! ¡Guapisma, guapisma!

—Que si sí, que si no, que si sería yo.

—Tú, gorrinón, ¿ande vas a ir? Debajo la artesa, ahi debajo la artesa.

—Que si sí, que si no, que si era yo.

— ¿Qué dice, madre? ¿Qué dice? Que si sí, que si no, que si sería ella.

-Tú, ¿ande vas a ir, gorrinón? No tiés qué vestirte ni na, no tiés qué ponerte.

Pues, ya va otra vez, y ya va otra vez el príncipe y las convida otra vez. Y se van otra vez la madre y la hija. Y la pobre Estrellita de Oro, debajo la artesa.

Bueno, ya se va y dice:

- Varica de la virtú, con la gracia que yo tengo y la que Dios me va a dar, si anoche me pusistes guapa, esta noche ponme más.

Bueno, baja y ya la Virgen la pone guapisma, guapisma. Y ya se va otra vez al baile. Y el hijo del rey, pos bailando, bailando, pero se llevó otro zapato y el hijo del rey, ¿qué hizo?, guardarlo el otro. Pues ya se va, venga a bailar, venga a bailar, venga a bailar, ya y a la hora que le dijo la Virgen, pues se fue.

Bueno, pues ¡hala!, se acaba el baile, se van. Y a otro día va el hijo del rey con el zapato:

-Que la que le venga este zapato me caso con ella.

Unas se cortaron un piazo pie, otras se cortaron un dedo pa que le viniera el zapato. Y le vino a venir al Rabo de Burro ¡hombre! Le viene al Rabo de Burro y llevaba el hijo del príncipe un... un coche con una perrica muchismo bonica. Y ya dice:

-Bueno, pero así que lleguemos al palacio te tienes que quitar eso, el pañuelo arrodeao.

Y sube en el coche y va la perra detrás:

— ¡Gua gua gua! La Estrellica de Oro debajo la artesa está y el Rabo de Burro en el coche va.

- ¿Pos qué dice?

-Pos na, pos que es tonta la perra.

— ¡Gua gua gua! La Estrellica de Oro debajo la artesa está y el Rabo de Burro en el coche va.

Dice:

-No, pero así que vayas al palacio te quitas el pañuelo y eso, el pañuelo pa que te presente a mis padres.

Bueno, pues ya llegan al palacio y se quita el pañuelo y tenía el rabo de burro ese allí en toa la frente. Pos claro, vino y se la... se la trae y se fue a su casa. Y entonces, se casó con la Estrellica de Oro. 


\section{Conclusiones}

A lo largo de este artículo hemos conocido a dos mujeres, con la misma formación, inmersas en un mismo contexto socioeconómico, pero con dos estilos de narrar distintos: una de ellas, Avelina, atraída por los cuentos de magia y los acumulativos, las rimas y la sonoridad; la otra, Paula, sencilla en su expresión verbal, rica en gestualidad. Su estilo está más próximo a la representación. Ambas demuestran un dominio de la situación y se nutren de la presencia del auditorio: Avelina, aferrada a la mano del receptor; Paula, ávida de risa al final de su performance. Tal vez por ese motivo siempre empieza narrando chistes y cuentos «coloraos» y, cuando se ha ganado a su público, narra otro tipo de cuentos. Por desgracia, algunos de ellos se han borrado de su memoria y solo quedan personajes perversos, doncellas desvalidas, fórmulas y aventuras inconclusas de la zorra y el lobo.

Las dos narradoras tenían en común las veladas mondando rosa del azafrán. Paula ha transmitido sus cuentos a sus vecinas. Los cuentos de Avelina son recordados con admiración, pero nadie — ni siquiera su hija — ha sido capaz de contarme ninguno. Aquellas trasnochadas acompasadas y monótonas han desaparecido. Sin embargo, en los atardeceres de Pozuelo se sigue manteniendo un espacio social para la conversación y el intercambio de anécdotas. Estoy convencida de que, gracias a ese espacio y al clima de cordialidad que se respira entre los vecinos, se resisten a desaparecer los cuentos de tradición oral.

\section{Referencias bibliográficas}

AARne, Antti; Stith Thompson (I96I): The Types of the Folktale. Folklore Fellows' Communications I84. Helsinki: Suomalainen Tiedeakatemia.

AgúNDEZ, José Luis (I999): Cuentos populares sevillanos (en la tradición oral y en la literatura). 2 vols. Sevilla: Fundación Machado.

AsıÁIN, Alfredo (2006): «Narraciones folklóricas navarras. Recopilación, clasificación y análisis». Cuadernos de Etnología y Etnografía de Navarra. 8I (enerodiciembre 2006): I-289.

Beltrán, Rafael (2007): Rondalles populars valencianes: Antologia, catàleg i estudi dins la tradició del folklore universal. Valencia: Universitat de València.

CARrillo, Pilar (2004): Això diu que era... Antropologia dels contes populars. Valencia: Carena editors.

Camarena, Julio; Maxime Chevalier (I995): Catálogo tipológico del cuento folklórico español. Cuentos maravillosos. Madrid: Gredos.

CARDigos, Isabel (2006): Catalogue of Portuguese Folktales. Folklore Fellows' Communications 29I. Helsinki: Suomalainen Tiedeakatemia.

Dundes, Alan (I980): Interpreting Folklore. Bloomington: University of Indiana Press.

GONZÁlez SANZ, Carlos (I996a): Catálogo tipológico de cuentos folklóricos aragoneses. Zaragoza: Instituto Aragonés de Antropología.

- (I996b): Despallerofant: recopilació i estudi de relats de tradició oral recollits a la comarca del Baix Cinca. Igualada: Institut d'Estudis del Baix Cinca. 
- (I998): «Revisión del Catálogo tipológico de cuentos folklóricos aragoneses: correcciones y ampliaciones». Temas de Antropología Aragonesa 8: 7-60.

- (2006): «La investigación folklórica: Premisas y consideraciones de carácter ético en relación con el trabajo de campo». En Rafael Beltrán; Marta Haro (eds.): El cuento folklórico en la literatura y en la tradición oral. Valencia: Universitat de València, p. 207-2I5.

- (20I0): De la chaminera al tejao... Antología de cuentos folklóricos aragoneses catalogados conforme a la Clasificación Internacional del Cuento-Tipo. 2 vols. Guadalajara: Palabras del Candil.

Hernández Fernández, Ángel (200I): Cuentos populares de la provincia de Albacete. Albacete: Instituto de Estudios Albacetenses «Don Juan Manuel» de la Excma. Diputación de Albacete.

- (2013): Catálogo tipológico del cuento folclórico en Murcia. El Jardín de la voz. Madrid: Publicaciones del Área de Teoría de la Literatura y Literatura Comparada de la Universidad de Alcalá, de la Universidad Nacional Autónoma de México (UNAM) y del Centro de Estudios Cervantinos.

IMAZ, Virginia (2005): «Charlando con Virginia Imaz». Tantágora n. ${ }^{\circ}$ I (otoño 2005): 39-43.

LAVINIO, Cristina (I990): «La formazione del titolo nel passaggio del racconto dall'oralità alla scrittura». La ricerca folklorica n. ${ }^{\circ}$ 2I (abril I990): II5-I2O.

— (I997): «Le forme della leggenda». La ricerca folklorica n. ${ }^{\circ} 36$ (octubre I997): 2532.

Mugnaini, Fabio (2004): «Tracce d'autore: Basile e il narratore di tradizione orale». En Albert Messerli; Michelangelo Picone (eds.): Giovanni Battista Basile e l'invenzione della fiaba. Ravenna: Longo, p. 275-304.

Noia CAMpos, Camiño (20IO): Catálogo tipolóxico do conto galego de tradición oral. Clasificación, antoloxía e bibliografía. Vigo: Servizo de Publicacións da Universidade de Vigo.

OrIOL, Carme; Josep M. Pujol (2003): Índex tipològic de la rondalla catalana. Barcelona: Departament de Cultura de la Generalitat de Catalunya. Centre de Promoció de la Cultura Popular i Tradicional Catalana.

- (2008): Index of Catalan Folktales. Folklore Fellows' Communications 294. Helsinki: Suomalainen Tiedeakatemia.

PÉrez, Juan Ignacio; Ana M. a MArTínez (2006): Cien cuentos populares andaluces recogidos en el Campo de Gibraltar. Algeciras: Asociación LitOral.

- (2009): Leyendas y cuentos de encantamiento recogidos junto al Estrecho de Gibraltar. Algeciras: Asociación LitOral.

Robe, Stanley (1972): Index of Mexican Folktales. Including Narrative Texts from Mexico, Central America, and the Hispanic United States. Berkeley-Los AngelesLondon: University of California Press.

Rodríguez DE LA TORRe, Fernando (2000): Dichos, coplas y versos tópicos de La Mancha y de la provincia de Albacete. Albacete: Instituto de Estudios Albacetenses «Don Juan Manuel» de la Excma. Diputación de Albacete. 
RODRÍGUEz PASTOR, Juan (2002): Cuentos extremeños de costumbres. Badajoz: Departamento de Publicaciones de la Diputación de Badajoz.

SANFILIPPO, Marina (2007a): El renacimiento de la narración oral en Italia y España (1985-2005). Madrid: Fundación Universitaria Española.

— (2007b): «Si cunta e s'arriccunta: las fórmulas de apertura y cierre en la narración oral». Revista de Dialectología y Tradiciones Populares LXII/ 2 (julio-diciembre 2007): I35-I63.

- (20I4): «Memoria, imágenes y escrituras en la elaboración de un cuento oral». Revista de Dialectología y Tradiciones Populares LXIX/I (enero-junio 20I4): I7II87.

Thompson, Stith (I932-36): Motif-Index of Folk-Literature. 6 vols. Bloomington: Indiana University Press.

UTHER, Hans-Jörg (2004): The Types of International Folktales. Folklore Fellows' Communications 284-286. Helsinki: Suomalainen Tiedeakatemia.

VENTURELLI, Gastone (I987): «La trasmissione della fiaba. Analisi di un caso familiare». La ricerca folklorica n. ${ }^{\circ}$ I2 (abril I987): 53-62. 